\title{
Normalising The Good Doctor ... and Other Health Services Personnel
}

\author{
Commentary on Deborah Oyer's Review of The Good Doctor
}

\author{
Letitia Helen Burridge
}

Received: 19 December 2013 / Accepted: 26 March 2014 /Published online: 25 April 2014

(C) Springer Science+Business Media Dordrecht 2014

The topic of Ron Paterson's book which was recently reviewed by Deborah Oyer only scratches the surface of a disturbing problem that is not confined to medicine, as health care delivery is a multidisciplinary experience for patients. I hear stories from patients about bullying dieticians, callous nurses, and institutions that espouse patient-centred care yet fail to deliver it to individuals who are unwell, worried, and vulnerable in an unfamiliar environment into which they have come for help. Maybe being conversant with standard guidelines and care pathways for specific health conditions makes it too easy forget that, for individual patients, ill health is a unique experience within their life-world. It could and should be our default approach as clinicians (and ancillary personnel) to acknowledge the fundamental competence that patients bring to health service encounters and to help them comprehend their options and the ramifications of their preferences within their lifeworld. Unless patients can explain to providers their life-world and its limitations and opportunities, gaps between advice-giving and advice-taking will remain and will influence health outcomes. Adjusting the system to ensure providers have enough time to listen more to their patients - and the will to do so - could be a useful starting point, as others (Barry et al. 2001) have suggested. The challenge, as Paterson's analysis of the situation implies, is to reach that point with consistency in each patient encounter. This will require personal as well as structural commitment.

\section{References}

Barry, C.A., F.A. Stevenson, N. Britten, N. Barber, and C.P. Bradley. 2001. Giving voice to the lifeworld. More humane, more effective medical care? A qualitative study of doctorpatient communication in general practice. Social Science and Medicine 53(4): 487-505.

Oyer, D. 2013. Review of The good doctor: What patients want, by Ron Paterson. Journal of Bioethical Inquiry 10(4): 519521. doi:10.1007/s11673-013-9485-0.

Paterson, R. 2012. The good doctor: what patients want. Auckland: Auckland University Press.

The original article by Deborah Oyer, published in the Journal of Bioethical Inquiry 10(4): 519-521, can be located at DOI 10.1007/ s11673-013-9485-0.

L. H. Burridge $(\square)$

NHMRC Centre of Research Excellence: Quality \& Safety in Integrated Primary-Secondary Care, Discipline of General Practice, School of Medicine, The University of Queensland, Herston, Queensland, Australia

e-mail: 1.burridge@uq.edu.au 